\title{
Dimensões que influenciam a percepção dos turistas sobre Destinos Turísticos Inteligentes
}

\section{Dimensions impacting tourists' perception of Smart Tourism Destinations}

\author{
Dimensiones que influyen en la percepción de los turistas sobre los \\ Destinos Turísticos Inteligentes
}

\section{Luiz Mendes Filho1; Verônica Feder Mayer²; Cynthia Harumy Watanabe Correa}

1 Programa de Pós-Graduação em Turismo (PPGTUR) da Universidade Federal do Rio Grande do Norte (UFRN), Natal, RN, Brasil

2 Faculdade de Turismo e Hotelaria da Universidade Federal Fluminense (UFF), Niteroi, RJ, Brasil

${ }^{3}$ Escola de Artes, Ciências e Humanidades (EACH), da Universidade de São Paulo (USP), São Paulo, SP, Brasil

Palavras-chave:

Destino Turístico Inteligente;

Tecnologia;

Inovação;

Sustentabilidade;

Acessibilidade.

Keywords:

Smart Tourism Destination; Technology; Innovation; Sustainability; Accessibility.
Palabras clave:

Destino Turístico Inteligente Tecnología;
Resumo

Um Destino Turístico Inteligente (DTI) tem como foco melhorar a experiência do turista, facilitada pela integração e utilização das Tecnologias da Informação e Comunicação (TIC) nas cidades. 0 objetivo desse estudo foi investigar como a percepção dos turistas sobre o "grau de inteligência" de um destino pode ser influenciada pelas dimensões de DTI definidas pela literatura: Sustentabilidade, Acessibilidade, Tecnologia e Inovação. Para isso, realizou-se uma pesquisa quantitativa com 303 turistas em visita às cidades de Natal, Rio de Janeiro e São Paulo. Pela Análise de Regressão Linear Múltipla, verificou-se que indicadores das dimensões Inovação e Sustentabilidade influenciaram a variável dependente DTI. Os indicadores com mais influência sobre DTI na percepção dos turistas foram: "Novas tecnologias utilizadas pelas empresas do setor turístico", "Projetos de inovação para melhoria de produtos e serviços turísticos", e "Planejamento urbanístico da cidade". Houve também correlações significativas, porém, baixas, entre variáveis de Tecnologia e Acessibilidade com DTI. Conclui-se que as dimensões mais percebidas pelos turistas são aquelas com maior potencial de retorno rápido e menos risco para os destinos, aumentando a competitividade, devendo receber atenção especial de gestores públicos e privados.

Abstract

A Smart Tourism Destination (STD) focuses on improving the tourist experience through the integrated use of Information and Communication Technologies (ICT) in cities. This study investigated how tourists' perception of the "degree of smartness" of a given destination can be influenced by the STD dimensions outlined by the specialized literature, namely Sustainability, Accessibility, Technology, and Innovation. To this end, we conducted a quantitative survey with 303 tourists visiting the cities of Natal, Rio de Janeiro, and São Paulo, Brazil. Multiple Linear Regression analysis revealed that the indicators associated with the Innovation and Sustainability dimensions influenced the STD dependent variable. The indicators with the most significant impact on STD according to tourists' perception were: "New technologies employed by companies in the tourism sector," "Innovation projects for improving tourism products and services," and "Urban planning." Although low, significant correlations were found between the variables associated with Technology and Accessibility and STD. We conclude that the dimensions most perceived by tourists are those with the most significant potential for rapid return and lower risk for destinations, which increase competitiveness and therefore require special attention from public and private managers.

Resumen

Un Destino Turístico Inteligente (DTI) se enfoca en mejorar la experiencia turística, facilitada por la integración y uso de las Tecnologías de la Información y la Comunicación (TIC) en las ciudades. El 
Innovación;

Sustentabilidad;

Accesibilidad.

Revisado em pares.

Recebido em: 21/12/2020.

Aprovado em: 12/05/2021.

Editor:

Glauber Eduardo de Oliveira Santos objetivo de este estudio fue investigar cómo la percepción de los turistas sobre el "grado de inteligencia" de un destino puede verse influida por las dimensiones de DTI definidas por la literatura: Sostenibilidad, Accesibilidad, Tecnología e Innovación. Para hacer esto, se realizó una investigación cuantitativa con 303 turistas que visitaban las ciudades de Natal, Río de Janeiro y São Paulo. Mediante el Análisis de Regresión Lineal Múltiple, se encontró que los indicadores de las dimensiones Innovación y Sostenibilidad influyeron en la variable dependiente DTI. Los indicadores con mayor influencia en la percepción de los turistas sobre DTI fueron: "Nuevas tecnologías utilizadas por las empresas del sector turístico", "Proyectos de innovación para mejorar los productos y servicios turísticos" y "Planificación urbana de la ciudad". También hubo correlaciones significativas, pero bajas, entre las variables de Tecnología y Accesibilidad con DTI. Así, las dimensiones más percibidas por los turistas son aquellas con mayor potencial de retorno rápido y menor riesgo a los destinos, aumentando la competitividad, y deben recibir atención por parte de los gestores públicos y privados.

Como Citar: Mendes Filho, L.; Mayer, V. F.; Correa, C. H. W. (2022). Dimensões que influenciam a percepção dos turistas sobre Destinos Turísticos Inteligentes. Revista Brasileira de Pesquisa em Turismo, São Paulo, 16, e-2332. http://dx.doi.org/10.7784/rbtur.v16.2332

\section{INTRODUÇÃO}

As Tecnologias da Informação e Comunicação (TIC) revolucionaram a atividade turística, ajudando a definir estratégias inovadoras e melhorando a competitividade das organizações e destinos (Buhalis, 2019). Devido à rápida evolução das TIC, o turismo, os destinos, e as experiências dos turistas não podem mais ser considerados como no passado (Femenia-Serra, Neuhofer, \& Ivars-Baidal, 2019). As TIC contribuem em termos de geração de experiências aos turistas, melhoram a eficiência na automação de processos para as organizações afins (Buhalis \& Amaranggana, 2015), e abrem um novo cenário para gestão de destinos (Ivars-Baidal, Celdrán-Bernabeu, Mazón, \& Perles-Ivars, 2019). Por exemplo, o uso de tecnologias móveis pelos turistas permite o consumo de informação personalizada, em qualquer hora e lugar no destino (Lamsfus, Martín, Alzua-Sorzabal, \& Torres-Manzanera, 2015; Jovicic, 2019). Os serviços móveis são capazes de adaptar-se às necessidades do visitante, pois consideram os dados das pessoas, como localização e arredores (geolocalização de destinos turísticos), bem como permitem o compartilhamento de experiências, e a compra e consumo de serviços turísticos, proporcionando uma nova visão sobre o consumo de um destino (Lamsfus, Wang, Alzua-Sorzabal, \& Xiang, 2015).

A revolução digital móvel levou ao surgimento do conceito de Destinos Turísticos Inteligentes (DTI), cujo foco é melhorar a experiência do turista, facilitada pela integração e utilização das TIC nas cidades (Neuhofer, Buhalis, \& Ladkin, 2012). De acordo com Lamsfus et al. (2015), um destino turístico é avaliado como inteligente quando utiliza intensivamente a infraestrutura tecnológica ofertada pela cidade a fim de: (1) melhorar a experiência dos viajantes, tornando-os conscientes de serviços e produtos turísticos disponíveis, e (2) capacitando organizações de gestão de destino, instituições locais e empresas de turismo para tomarem decisões e realizarem ações apoiados em dados produzidos, administrados e processados por meio da infraestrutura tecnológica no âmbito do destino.

A temática de destino e turismo inteligente tem atraído a atenção de integrantes da cadeia produtiva do turismo, como profissionais, governos (federal, estadual e municipal) e pesquisadores (Mehraliyev, Choi, \& Köseoglu, 2019). 0 assunto é relevante para profissionais e gestores públicos e privados devido à alta capacidade de fornecer dados significativos e inovadores, promovendo interconectividade entre as partes interessadas na atividade turística (Johnson \& Samakovlis, 2019; Williams, Rodriguez, \& Makkonen, 2020). DTI é também uma área promissora de pesquisa em termos de modelos e estratégias para o processo de configuração inteligente nos destinos (Vecchio, Mele, Ndou, \& Secundo, 2018). Além disso, o DTI visa oferecer experiências personalizadas aos turistas pelo uso das TIC, podendo permitir o sucesso e ampliação da competitividade dos destinos, e melhorar a qualidade de vida de maneira sustentável dos residentes (Cimbaljević, Stankov, \& Pavluković, 2019; Femenia-Serra, Perles-Ribes, \& Ivars-Baidal, 2019). Assim, os destinos estão redefinindo papéis e lógicas empresariais envolvendo os turistas como cocriadores das próprias experiências, utilizando novas tecnologias para definir produtos turísticos (Buonincontri \& Micera, 2016).

Apesar da experiência do turista ser um aspecto central discutido pela literatura de DTI, nota-se uma escassez de pesquisas empíricas sobre as necessidades e preferências dos turistas sob a perspectiva do turismo inteligente (Femenia-Serra, Neuhofer et al., 2019; Gajdosík, 2019). Pesquisas sobre DTI focadas nos turistas já foram 
realizadas, mas com dados secundários e ressaltando casos de melhores práticas (Femenia-Serra, Neuhofer et al., 2019). A perspectiva do turista é ainda encontrada em estudos conduzidos no Brasil, Espanha e Eslováquia (Femenia-Serra \& Ivars-Baidal, 2018; Femenia-Serra, Perles-Ribes et al., 2019; Gajdosík, 2019; Santos \& Gândara, 2019), mas não existem pesquisas empíricas com uma ampla abrangência geográfica, com técnicas estatísticas avançadas e nem utilizando algum modelo teórico de DTI.

Nessa conjuntura, o objetivo desta pesquisa foi investigar como a percepção dos turistas sobre o "grau de inteligência" de um destino pode ser influenciada pelas dimensões de DTI definidas pela literatura, com ênfase no modelo teórico desenvolvido na Espanha pela Sociedad Mercantil Estatal para la Gestión de la Innovación y las Tecnologías Turísticas (SEGITTUR, 2016). No modelo SEGITTUR, as dimensões Sustentabilidade, Acessibilidade, Tecnologia e Inovação são aliadas para melhorar a competitividade nos destinos turísticos. Para alcançar o objetivo, foram escolhidos três destinos turísticos brasileiros com diferentes perfis: Natal, Rio de Janeiro e São Paulo, onde ocorreram as coletas de dados entre os meses de junho de 2019 a março de 2020. Além da importância para o turismo nacional, São Paulo e Rio de Janeiro ocupam relevantes posições no ranking Connected Smart Cities 2020 (URBAN SYSTEM, 2020). Já Natal aderiu à Rede Brasileira de Cidades Inteligentes e Humanas, em parceria com o Instituto Metrópole Digital (IMD), da UFRN (Mendes Filho, Silva, \& da Silva, 2019). A Análise de Regressão Linear Múltipla foi empregada para validação do modelo teórico resultante.

\section{DESTINOS TURÍSTICOS INTELIGENTES (DTI)}

O turismo inteligente pode ser conceituado como um sistema de apoio turístico individual, com serviços de informação onipresentes, integração de fluxos de informações turísticas, e oferta de informação personalizada para o turista (Li, Hu, Huang, \& Duan, 2017). O turismo inteligente fornece insights práticos para stakeholders envolvidos na cocriação de valor na cadeia produtiva do setor, incluindo turistas; residentes; governos (municipais, estaduais e federais); autoridades de planejamento urbano, regional e turístico; organizações de gerenciamento de destino (DMO); agências de viagens e operadores turísticos; organizações de hospitalidade, lazer e patrimônio cultural; empresas e instituições públicas e privadas; e universidades (Koo, Mendes-Filho, \& Buhalis, 2019). De acordo com Gretzel, Sigala et al. (2015), há três componentes básicos no turismo inteligente: DTI, ecossistemas de negócios inteligentes e experiências inteligentes, todos com o suporte do processamento e troca de dados e informação entre as partes interessadas.

Um DTI compreende um sistema vinculado aos visitantes e aos cidadãos que se interliga a todas as organizações turísticas do destino, permitindo a obtenção de dados e serviços em tempo real (Buhalis \& Amaranggana, 2014; Boes, Buhalis, \& Inversini, 2015). O desenvolvimento de um DTI facilita o acesso direto aos serviços de valor agregado por meio de TIC avançadas, por exemplo, o acesso às informações em tempo real sobre a rede de transporte público, enriquecendo experiências turísticas e aumentando a competitividade do destino perante os concorrentes (Buhalis \& Amaranggana, 2014; Buonincontri \& Micera, 2016; Jeong \& Shin, 2019). Possibilitar inteligência de dados e informações ao DTI pode facilitar o processo de integração entre produção e consumo de produtos/serviços, aumentando o vínculo entre fornecedores e consumidores na cadeia produtiva do turismo (Jovicic, 2019).

Além disso, um DTI para alcançar a vantagem competitiva precisa oferecer experiência turística e garantir atratividade em comparação aos destinos vizinhos (Cimbaljević et al., 2019). Tecnologias como Internet das coisas, Big Data e dispositivos móveis permitirão aos destinos uma melhor compreensão sobre o comportamento dos turistas nesse ambiente de inteligência de dados, reduzindo incertezas sobre hábitos de consumo (Femenia-Serra, Neuhofer et al., 2019; Williams et al., 2020). Os DTI devem prestar atenção ao aprimoramento da experiência memorável dos turistas a partir de tecnologias como realidade aumentada e realidade virtual (Jeong \& Shin, 2019).

O foco central de um DTI são os turistas inteligentes, grupo que se beneficia do turismo inteligente usando TIC disponíveis nos DTI (Gretzel et al., 2018; Femenia-Serra, Neuhofer et al., 2019). Um DTI tem a capacidade de oferecer experiências personalizadas aos turistas devido ao acesso, coleta e análise de dados pessoais, estabelecendo padrões de uso e facilitando a previsão de necessidades e a melhoria dos serviços (Buhalis \& Amaranggana, 2015). O turista inteligente geralmente compartilha dados (informações pessoais básicas, preferências, informações de perfis em redes sociais, localização e movimentação, despesas) com outros stakeholders, desde que se sinta confiante com o uso potencial desses dados. Assim, o turista entende que os benefícios obtidos valerão a pena e assume que sua privacidade e segurança serão protegidas (Femenia-Serra, 
Neuhofer et al., 2019). Portanto, a meta de um DTI é aperfeiçoar a experiência turística maximizando a competitividade do destino e a satisfação do visitante (Vecchio et al., 2018).

\section{EVOLUÇÃO DAS PESQUISAS SOBRE DTI}

Houve um aumento significativo de artigos publicados sobre turismo e destinos inteligentes, sendo necessário, nesse momento, avaliar o progresso do conhecimento científico sobre a temática (Johnson \& Samakovlis, 2019; Mehraliyev et al., 2019). No início, os estudos eram mais teóricos e concentrados em conceitos e frameworks de pesquisa, por exemplo, Buhalis e Amaranggana (2014, 2015) desenvolveram um framework para DTI por meio da exploração de aplicações turísticas nos destinos. Outros estudos criaram conceitos de turismo inteligente e definiram bases tecnológicas e comerciais para DTI (Gretzel, Sigala et al., 2015), como também bases para compreensão de ecossistemas de turismo inteligente (Gretzel, Werthner, Koo, \& Lamsfus, 2015).

Em seguida, destacaram-se estudos de casos fundamentados em pesquisas bibliográficas e documentais de fontes governamentais, acadêmicas e da internet, sobre cidades importantes europeias, como Barcelona, Amsterdam e Helsinki, para identificar componentes de DTI (Boes et al., 2015; Boes, Buhalis, \& Inversini, 2016). Pesquisas descritivas no Brasil, China e Coreia do Sul apresentaram iniciativas de DTI e de criação de infraestruturas tecnológicas para desenvolvimento de turismo inteligente (Wang, Li, \& Li, 2013; Cacho et al., 2016; Gretzel et al., 2018). Posteriormente, surgiram estudos de casos realizados na Espanha, em Benidorm e Málaga (Santos Júnior, Mendes Filho, García, \& Simões, 2017; Femenia-Serra \& Ivars-Baidal, 2018), e no Brasil, em Curitiba, Florianópolis e Natal (Gomes, Gândara, \& Ivars-Baidal, 2017; Mendes Filho et al., 2019; Santos-Júnior, Biz, Almeida-García, \& Mendes-Filho, 2019; Freitas \& Mendes Filho, 2020).

Embora haja diversos estudos sobre DTI (Johnson \& Samakovlis, 2019; Mehraliyev et al., 2019), ainda existem lacunas a serem preenchidas, principalmente em termos empíricos. Para Mehraliyev, Chan, Choi, Koseoglu e Law (2020), a área menos pesquisada de DTI refere-se à preferência dos consumidores pelo turismo inteligente nos destinos. Por exemplo, estudos sobre segmentação no contexto de DTI são essenciais para compreender aspectos como: quais turistas preferem o turismo inteligente, qual a motivação e em que grau preferem o turismo inteligente, e quais aspectos do turismo inteligente preferem (Mehraliyev et al., 2020).

Quanto às pesquisas sobre DTI enfocando turistas e residentes, elas geralmente utilizam dados secundários e descrevem casos de melhores práticas para identificar atributos do tipo de turista, suas características e seu papel no contexto de DTI (Femenia-Serra, Neuhofer et al., 2019). Em termos de pesquisa empírica, são ilustrativos um estudo descritivo que verificou a experiência dos turistas em São Luís no Maranhão (Santos \& Gândara, 2019) e outros dois na Espanha. O primeiro verificou que a expectativa colocada na abordagem sobre DTI é justificada pela percepção tecnológica da demanda turística por estudantes de turismo espanhóis (Femenia-Serra, Perles-Ribes et al., 2019), enquanto o segundo constatou que os esforços dos DTI estão transformando o gerenciamento de destinos, os processos de marketing e as experiências dos turistas (Femenia-Serra \& Ivars-Baidal, 2021). Houve também um estudo na Eslováquia que examinou se "turistas inteligentes" são um segmento de mercado real, analisando as diferenças no comportamento de viagens deste segmento (Gajdosík, 2019). E há um modelo teórico sobre a qualidade de vida dos residentes em DTI proposto com base em uma análise sistematizada da literatura, mas que ainda necessita ser validado empiricamente (Santos-Júnior, Almeida-García, Morgado, \& Mendes-Filho, 2020).

Estudar DTI com o olhar nos turistas é relevante para aprimorar as experiências dos viajantes por meio de serviços mais inteligentes que interconectem todos os stakeholders, integrando dados da cadeia produtiva e permitindo tomadas de decisão em tempo real (Femenia-Serra, Neuhofer et al., 2019). Experiências de turistas em DTI podem gerar uma satisfação maior e, consequentemente, a intenção de retornar ao destino (Jeong \& Shin, 2019). Por estas razões, o estudo escolheu o turista como sujeito central de investigação.

\section{METODOLOGIA}

A pesquisa tem como objetivo investigar como a percepção dos turistas sobre o "grau de inteligência" de um destino pode ser influenciada pelas seguintes dimensões de DTI: Sustentabilidade, Acessibilidade, Tecnologia e Inovação. A investigação apresentou caráter exploratório-descritivo no que concerne aos objetivos, tendo como enfoque nos resultados principais a abordagem quantitativa, utilizando também um estudo qualitativo inicial para definição dos itens das dimensões a serem utilizados na survey final do estudo. 
Na primeira etapa, foi realizada uma pesquisa bibliográfica combinada a um levantamento documental. Esperouse, portanto, que a pesquisa bibliográfica e documental permitisse identificar as metodologias e dimensões recomendadas para avaliação de DTI. A pesquisa bibliográfica se baseou nas seguintes bases de dados: Science Direct, EBSCO, Portal de Periódico da CAPES/MEC, Google Acadêmico e Banco de dados “Publicações de Turismo" do PPGTUR da EACH-USP. Enquanto que o levantamento documental concentrou-se em normas e regulamentos utilizados pelo governo espanhol por meio da SEGITTUR (2016), como as normas da Asociación Española de Normalización y Certificación (AENOR).

A Espanha é considerada uma das referências mundiais na área de DTI (INVAT.TUR, 2015; SEGITTUR, 2016), e a SEGITTUR é uma sociedade pública espanhola dedicada à gestão da inovação e tecnologias no turismo. Entre as normas observadas, a eleita como base para o estudo foi a UNE 178501, de abril de 2016, que trata objetivamente do Sistema de Gestão de DTI. Essa norma apresenta um modelo teórico para DTI com intuito de ajudar destinos interessados em desenvolver práticas de turismo inteligente. Os DTI vêm ganhando importância à medida que modelos teóricos são aplicados para entender o impacto das novas TIC no relacionamento entre governo, empresas, turistas e destinos (Femenia-Serra, Neuhofer et al., 2019). Assim, a norma UNE 178501 da SEGITTUR (2016) norteia este trabalho a partir das quatro dimensões recomendadas para se avaliar um DTI: Sustentabilidade, Acessibilidade, Tecnologia e Inovação (Figura 1).

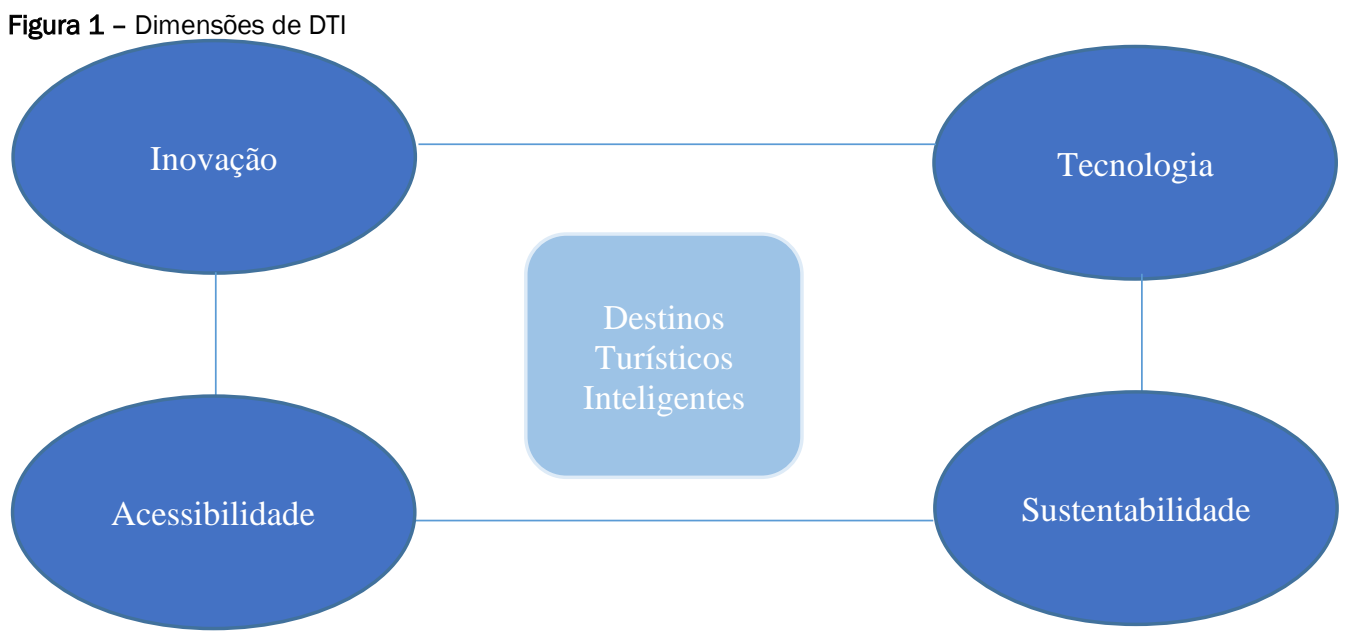

Fonte: Adaptado de SEGITTUR (2016)

A SEGITTUR (2016) apresenta os seguintes conceitos de cada dimensão:

- $\quad$ Sustentabilidade: associa a proteção da atividade econômica do turismo no presente e futuro ao respeito ambiental no curto, médio e longo prazos, à preservação de valores socioculturais do destino, assegurando a qualidade de vida dos residentes de hoje e futuros;

- $\quad$ Acessibilidade: abrange o desenvolvimento de um turismo que permita o acesso, uso e gere prazer a todos os turistas, sem exceção, concedendo-Ihes o direito à igualdade de oportunidades para utilizar ambientes, serviços, bens, tecnologias e produtos, de forma mais segura, confortável e autônoma possível;

- Tecnologia: refere-se ao grau de uso e utilidade de tecnologias pelos turistas para satisfazer as necessidades e anseios desde o planejamento da viagem até a realização da viagem em si;

- Inovação: compreende a introdução ou melhoria de novos serviços, processos, métodos de organização nas práticas de gestão do destino e na relação com os residentes e turistas, visando melhorar a competitividade do destino.

Realizou-se, também, uma pesquisa documental no manual operacional espanhol para configuração de DTI, criado pelo Instituto Valenciano de Tecnologias Turísticas (INVAT.TUR, 2015), que propõe um modelo de gestão com itens/indicadores para a transformação de destinos em DTI. Os indicadores do INVAT.TUR baseiam-se na realidade dos destinos da Comunidade Valenciana, e foram definidos por profissionais e especialistas de diferentes áreas relacionadas a cidades e destinos inteligentes na Espanha. 
A segunda etapa consistiu em uma abordagem qualitativa por meio da condução de entrevistas em profundidade semiestruturadas durante 2018/19. O objetivo dessas entrevistas foi verificar experiências em DTI, de modo a consolidar os itens e as dimensões de DTI identificadas nas pesquisas bibliográfica e documental da primeira etapa. $\mathrm{Na}$ Inglaterra, foi entrevistado um professor da School of Tourism da Bournemouth University, referência em pesquisas sobre DTI (Boes et al., 2015, 2016; Buhalis \& Amaranggana, 2014). No Rio de Janeiro, foram entrevistados dois gestores públicos e dois pesquisadores da UFF, relacionados à atividade turística no estado. Em São Paulo, foram entrevistados dois gestores públicos e dois pesquisadores da USP, ligados ao turismo no estado. Enquanto em Natal, os entrevistados foram quatro gestores dos setores público e privado relacionados ao setor turístico no Rio Grande do Norte, além de dois pesquisadores da UFRN. As três instituições brasileiras possuem pesquisadores com experiência em estudos sobre DTI (Lima, Mendes Filho, Correa, \& Mayer, 2021).

A partir deste conjunto de informações, elaborou-se um questionário (Tabela 1) para identificar quais dimensões de DTI influenciam a percepção dos turistas sobre o grau de inteligência dos destinos, que foi aplicado por meio de uma survey com turistas nas cidades selecionadas. Antes de aplicar a survey, um teste piloto foi realizado para avaliar os padrões do questionário, ao se obter feedback sobre o nível de entendimento das perguntas para possíveis adequações referentes às dimensões a serem testadas, bem como fornecer uma noção do tempo de resposta médio. O piloto ocorreu em março de 2019, somando 20 questionários respondidos por alunos de pósgraduação em Natal. Em seguida, foram realizados ajustes no instrumento de pesquisa para a posterior coleta final.

O formulário é composto por 30 questões fechadas e dividido em duas partes. Nas 20 questões iniciais, os turistas foram questionados sobre a percepção acerca das quatro dimensões de DTI: Sustentabilidade, Acessibilidade, Tecnologia e Inovação (Tabela 1). Em todos os itens, foi utilizada a escala de Likert de cinco pontos, sendo: (1) discordo totalmente; (2) discordo parcialmente; (3) nem discordo, nem concordo; (4) concordo parcialmente; e (5) concordo totalmente. A última pergunta desse bloco teve como objetivo medir o grau de inteligência do destino, quando o turista avaliou se percebia a cidade como um DTI. No segundo bloco de questões, havia nove perguntas sobre o perfil do respondente, como: gênero, idade, estado civil, renda familiar mensal, entre outras.

Tabela 1 - Dimensões e itens para avaliar DTI

\begin{tabular}{|c|c|}
\hline Dimensões & Itens \\
\hline Sustentabilidade & $\begin{array}{l}\text { planejamento urbanístico } \\
\text { mobilidade urbana pelas ruas } \\
\text { energia elétrica pela cidade } \\
\text { coletores de lixo pela cidade } \\
\text { prédios públicos conservados }\end{array}$ \\
\hline Acessibilidade & $\begin{array}{l}\text { acessibilidade nas ruas para turistas com deficiência física, auditiva ou visual } \\
\text { transporte público adaptado para turistas com deficiência física, auditiva ou visual } \\
\text { atrativos turísticos acessíveis para turistas com deficiência física, auditiva ou visual } \\
\text { serviços de informação adaptados para turistas com deficiência física, auditiva ou visual } \\
\text { existência de aparelhos/instalações para turistas com deficiência física, auditiva ou visual }\end{array}$ \\
\hline Tecnologia & $\begin{array}{l}\text { Wi-fi disponível pela cidade } \\
\text { conexão rápida pela operadora de internet na cidade } \\
\text { aplicativos turísticos com informações da cidade } \\
\text { sites com informações turísticas da cidade } \\
\text { perfis de redes sociais com informações turísticas da cidade }\end{array}$ \\
\hline Inovação & $\begin{array}{l}\text { inovações na organização turística municipal } \\
\text { projetos de inovação para melhoria de produtos e serviços turísticos } \\
\text { novas tecnologias como QRcode, RFID, NFC etc. adotadas por empresas do setor turístico (hotéis, } \\
\text { restaurantes, bares etc.) } \\
\text { promoções de última hora para venda de produtos e serviços turísticos } \\
\text { diferentes serviços turísticos comparados a outros destinos }\end{array}$ \\
\hline
\end{tabular}

Fonte: Os autores (2019)

Os dados coletados foram processados pelo software Statistical Package for the Social Sciences (SPSS) da empresa IBM, versão 26 para Windows. Para a análise dos dados, utilizou-se inicialmente a estatística descritiva para conhecer o perfil sociodemográfico dos turistas, como também a percepção dos turistas sobre as dimensões (Sustentabilidade, Acessibilidade, Tecnologia e Inovação) de DTI por cidade. Em seguida, calcularam-se os valores dos coeficientes de Pearson para investigar o grau de correlação entre as variáveis de cada dimensão com a 
variável DTI. Por fim, utilizou-se a Regressão Linear Múltipla para analisar se há variância dos itens (variáveis independentes) de cada dimensão sobre a variável dependente DTI por diferente cidade.

A população do estudo foi constituída por turistas em visita a Natal, ao Rio de Janeiro e a São Paulo. Os pontos de coleta foram definidos conforme os locais de maior fluxo de turistas de cada cidade, sendo respondidos 303 questionários. A divisão por cidade ficou assim: 100 questionários em junho/julho de 2019 na praia de Ponta Negra em Natal; 103 questionários em novembro/dezembro de 2019 no centro da cidade do Rio de Janeiro; e 100 questionários em fevereiro/março de 2020 no aeroporto de Guarulhos em São Paulo. A amostra foi do tipo não probabilística, com seleção de turistas aleatoriamente ou por acessibilidade.

Seguindo as regras de Hair Jr., Black, Babin, Anderson e Tatham (2009), para calcular o tamanho da amostra em Regressão Linear Múltipla é necessário haver cinco observações para cada variável independente. Como existem 20 variáveis independentes no estudo e o mínimo é de cinco respondentes por variável, o mínimo exigido é 100 questionários para analisar os resultados da regressão. Desta forma, a pesquisa alcançou o mínimo exigido para Regressão Linear Múltipla, pois foram coletados pelo menos 100 questionários de turistas por cidade (Natal, Rio de Janeiro e São Paulo).

\section{ANÁLISE DOS RESULTADOS}

Essa seção do artigo está dividida em cinco partes: 1) Perfil sociodemográfico da amostra; 2) Análise descritiva das dimensões de DTI (Sustentabilidade, Acessibilidade, Tecnologia e Inovação) e DTI (grau de inteligência percebido nos destinos); 3) Correlação de Pearson das variáveis, quando se investigou o grau de correlação entre as variáveis de cada dimensão com a variável DTI; 4) Análise de Regressão Linear Múltipla do modelo teórico proposto; e 5) Discussão dos principais resultados encontrados na análise de regressão linear múltipla e correlação de Pearson.

\subsection{Perfil sociodemográfico da amostra}

$\mathrm{Na}$ amostra total da pesquisa (303 respondentes) houve maior presença de pessoas do sexo feminino (56\%), com um melhor equilíbrio entre os gêneros verificado em São Paulo. Os turistas entrevistados eram, em sua maioria, jovens adultos (60\% entre 25 e 44 anos), casados (44\%) ou solteiros (45\%), com formação de nível superior e pósgraduação (74\%), sendo que os níveis mais altos de escolaridade foram predominantes nas amostras de São Paulo (78\%) e do Rio de Janeiro (81\%). Metade dos respondentes declarou renda superior a R $\$ 5.001,00$, e aproximadamente um terço declarou renda entre $\mathrm{R} \$ 3.001,00$ e $\mathrm{R} \$ 5.000,00$, com turistas de maior renda presentes em São Paulo, o que reflete o mercado local.

No que se refere à viagem, a maioria (72\%) dos respondentes já havia visitado as cidades duas vezes ou mais. Em Natal (78\%) e no Rio de Janeiro (83\%), uma grande proporção dos entrevistados tinha o lazer como principal motivo da viagem, sendo que em São Paulo as motivações para negócios e lazer foram mais equilibradas (48\% e 52\%, respectivamente). Todavia, ao se analisar as três cidades em conjunto, o total de turistas a lazer foi de $71 \%$. Por fim, a maioria dos entrevistados (77\%) permaneceu na cidade por mais de 3 noites. Sendo assim, a amostra foi composta por indivíduos com experiência nos destinos, o que indica boa capacidade para avaliá-los nos quesitos da pesquisa (Tabela 2).

\begin{tabular}{clr} 
Tabela 2 - Perfil da Amostra & (continua) \\
\hline \multirow{2}{*}{ Variável } & Categoria & Total \\
\hline \multirow{4}{*}{ Faixa etária } & Feminino & $56 \%$ \\
& Masculino & $44 \%$ \\
\hline & 18 a 24 & $15 \%$ \\
& 25 a 34 & $36 \%$ \\
& 35 a 44 & $24 \%$ \\
& 45 a 54 & $15 \%$ \\
& 55 a 64 & $7 \%$ \\
& 65 ou mais & $3 \%$ \\
\hline \multirow{3}{*}{ Estado civil } & Solteiro(a) & $44 \%$ \\
& Casado(a) & $45 \%$ \\
& Separado(a) & $5 \%$ \\
& Viúvo(a) & $4 \%$ \\
& Outro & $2 \%$ \\
\hline
\end{tabular}




\begin{tabular}{|c|c|c|}
\hline Variável & Categoria & Total \\
\hline \multirow{5}{*}{ Renda } & Até $\mathrm{R} \$ 1.000$ & $3 \%$ \\
\hline & De $R \$ 1.001$ a $R \$ 3.000$ & $14 \%$ \\
\hline & De $R \$ 3.001$ a $R \$ 5.000$ & $33 \%$ \\
\hline & De $R \$ 5.001$ a $R \$ 9.000$ & $36 \%$ \\
\hline & Acima de $\mathrm{R} \$ 9.001$ & $14 \%$ \\
\hline \multirow{4}{*}{ Escolaridade } & Fundamental & $3 \%$ \\
\hline & Médio & $22 \%$ \\
\hline & Superior & $54 \%$ \\
\hline & Pós-graduação & $20 \%$ \\
\hline \multirow{2}{*}{ Visita à cidade } & $1 \mathrm{vez}$ & $28 \%$ \\
\hline & 2 vezes ou mais & $72 \%$ \\
\hline \multirow{5}{*}{ Motivação principal } & Negócios e outros & $29 \%$ \\
\hline & Lazer & $71 \%$ \\
\hline & Tempo de permanência & Total \\
\hline & 1 ou 2 noites & $23 \%$ \\
\hline & 3 noites ou mais & $77 \%$ \\
\hline
\end{tabular}

Fonte: Os autores (2020)

\subsection{Análise descritiva das dimensões de DTI}

A partir dos resultados sobre a dimensão Sustentabilidade, na percepção dos turistas que visitaram Natal, Rio de Janeiro e São Paulo, as cidades disponibilizam energia elétrica pelas ruas, devido às maiores médias absolutas alcançadas nos três destinos (respectivamente, 4,31, 4,17 e 4,19). Outros itens de Sustentabilidade com boas médias de concordância na percepção dos turistas foram: coletores de lixo em Natal $(4,0)$, e mobilidade urbana pelas ruas do Rio de Janeiro $(3,80)$.

Quanto à dimensão Acessibilidade, nota-se que os respondentes não manifestaram um alto grau de concordância sobre as cidades possuírem transportes públicos adaptados para turistas com deficiências física, auditiva ou visual, com as médias nas três cidades: Rio de Janeiro $(3,19)$, São Paulo $(2,97)$ e Natal $(2,89)$. Na sequência, destacamse outras questões de Acessibilidade que alcançaram avaliações medianas de concordância na percepção dos viajantes: atrativos turísticos acessíveis para turistas com deficiências em Rio de Janeiro e São Paulo (3,21 e 2,98), serviços de informação adaptados para turistas com deficiências no Rio de Janeiro $(3,18)$, e existência de instalações/aparelhos para turistas com deficiências em Natal $(2,98)$.

Pelos resultados referentes à dimensão de Tecnologia, os turistas que estiveram em São Paulo, Rio de Janeiro e Natal concordaram que as cidades forneciam conexão rápida via operadora de Internet, devido à alta média alcançada nos destinos (respectivamente, 4,50, 4,11 e 3,83). Outras tecnologias com boas médias de concordância na percepção dos turistas foram: sites com informações turísticas da cidade do Rio de Janeiro e Natal $(3,75$ e 3,50), perfis de redes sociais com informações turísticas do Rio de Janeiro e São Paulo (3,74 e 3,21), e aplicativos turísticos da cidade do Rio de Janeiro $(3,58)$.

Relativo à dimensão de Inovação, os turistas em visita a São Paulo concordaram que as Novas tecnologias (QRcode, RFID, NFC etc.) utilizadas por empresas do setor turístico é uma forma de Inovação oferecida pelo destino, pois alcançou a maior média nesse quesito $(3,85)$. Enquanto a maior média de concordância de Inovação no Rio de Janeiro, na percepção dos turistas, contemplou os diferentes serviços turísticos comparados a outros destinos $(3,84)$, e em Natal abrangeu as promoções de última hora para venda de serviços turísticos $(3,70)$.

Após a avaliação das quatro dimensões, os turistas foram convidados a indicar o quanto o destino poderia ser considerado inteligente. Com relação à avalição da variável DTI, sobre o grau de inteligência dos destinos, os resultados indicaram que, em uma escala de 1 a 5, São Paulo obteve a melhor avaliação como um DTI na percepção dos turistas (Média = 3,68; Desvio Padrão = 1,15), seguida pelo Rio de Janeiro com uma boa avaliação (Média = 3,05; Desvio Padrão = 0,65) e, finalmente Natal, que obteve a avaliação mais baixa e mediana sobre o desempenho como um DTI (Média = 2,55; Desvio Padrão = 1,14). Nesse sentido, os dados reforçam as posições do ranking Connected Smart Cities 2020, caracterizando a liderança das cidades paulistana e carioca em nível nacional (URBAN SYSTEM, 2020). Além de demarcar que os turistas passaram a perceber as estratégias de DTI implantadas por São Paulo, por exemplo. 


\subsection{Correlação de Pearson das variáveis}

Nesse estudo foram calculados os valores dos coeficientes de Pearson (r), para se investigar o grau de correlação entre as variáveis de cada dimensão (Sustentabilidade, Acessibilidade, Tecnologia e Inovação) com a variável DTI. Para Corrar, Paulo e Dias Filho (2007), duas variáveis podem ser altamente correlacionadas se mudanças ocorridas em uma variável estiver fortemente relacionada a mudanças ocorridas com a outra variável. Portanto, o coeficiente de correlação mensura a força do relacionamento entre duas variáveis. Existe uma correlação linear forte entre as variáveis analisadas quando os valores (positivos ou negativos) dos coeficientes de Pearson estiverem entre 0,60 e 0,99; uma correlação linear moderada quando estiverem entre 0,30 e 0,59; e uma correlação linear baixa entre as variáveis quando estiverem entre 0,10 e 0,29 (Corrar et al., 2007). E para analisar o nível de significância da relação entre as variáveis, a correlação é percebida como significativa se o valor de ( $p$ ) encontrado for menor que 0,05 (Corrar et al., 2007).

A partir dos valores obtidos dos coeficientes de Pearson da dimensão Sustentabilidade, existe correlação significativa positiva entre Planejamento urbanístico e DTI nas três cidades examinadas, variando entre moderada e baixa $(0,458 ; 0,291 ; 0,229)$. Houve destaque para São Paulo, cujo coeficiente de Pearson apresentou uma correlação moderada positiva de 0,458 e significativa entre Planejamento urbanístico e DTI, representando o maior coeficiente de correlação em Sustentabilidade entre as cidades. Outro dado é que todas as correlações das cinco variáveis de Sustentabilidade com DTI em São Paulo obtiveram coeficientes de Pearson significativos, com destaque para Planejamento urbanístico e Prédios públicos conservados $(0,333)$.

A dimensão Acessibilidade obteve coeficientes de Pearson com correlação moderada positiva e significativa entre as variáveis de Atrativos turísticos acessíveis para turistas com deficiências e DTI nas cidades de Natal e Rio de Janeiro $(0,396$ e 0,300$)$, enquanto em São Paulo a correlação foi também positiva significativa, porém baixa $(0,233)$. Apresentou correlação positiva baixa nas variáveis Transporte público adaptado e acessibilidade nas ruas para turistas com deficiências comparando à variável DTI nas três cidades, fixando os coeficientes de Pearson entre 0,162 e 0,264. Vale realçar que todas as correlações das variáveis de Acessibilidade com DTI em Natal obtiveram coeficientes de Pearson significativos, com ênfase em Atrativos turísticos acessíveis para turistas com deficiências.

Em termos de Tecnologia, foram registrados coeficientes de Pearson com correlações baixas e significativas nas variáveis Aplicativos turísticos com informações da cidade e Wi-Fi disponível comparando com DTI em Natal e Rio de Janeiro, variando os coeficientes de Pearson entre 0,182 e 0,265. Houve destaque para Natal, cujo coeficiente de Pearson apresentou uma correlação baixa positiva de 0,299 e significativa entre Perfis de redes sociais com informações turísticas da cidade e DTI (maior coeficiente de correlação na dimensão de Tecnologia entre todas as cidades). Igualmente, identificou-se uma correlação baixa positiva de 0,251 entre Sites com informações turísticas da cidade e DTI. Por outro lado, não foi observada correlação significativa entre as variáveis de Tecnologia com DTI na cidade de São Paulo.

Sobre os valores obtidos dos coeficientes de Pearson da dimensão Inovação, verifica-se que existe correlação moderada e significativa entre Novas tecnologias (QRcode, RFID, NFC etc.) adotadas por empresas do setor turístico e DTI nas três cidades $(0,654,0,300$ e 0,466). Há ainda outras variáveis de Inovação que alcançaram coeficientes de Pearson significativos (moderados ou baixos) nas três cidades, como: Projetos de inovação para melhoria de serviços turísticos $(0,530,0,313$ e 0,214) e Inovações na organização turística municipal $(0,523,0,243$ e 0,210). Salienta-se que as correlações das cinco variáveis de Inovação com DTI em Natal obtiveram coeficientes de Pearson moderados significativos, variando os coeficientes de Pearson entre 0,430 e 0,654.

\subsection{Análise de Regressão Linear Múltipla}

Para verificar como a percepção dos turistas sobre o "grau de inteligência" de um destino (variável dependente DTI) pode ser influenciada pelas dimensões Sustentabilidade, Acessibilidade, Tecnologia e Inovação, foi realizada uma Análise de Regressão Linear Múltipla. É importante mencionar que foi atestada a ausência de multicolinearidade pelo fator de inflação de variância (VIF) e pelo valor de tolerância dos dados. Segundo Hair Jr. et al. (2009), o ideal é que o valor de Tolerância seja acima de 0,10, e o valor VIF inferior a 10. 0 valor mínimo de Tolerância para os resultados de Natal, Rio de Janeiro e São Paulo foi de 0,74 e o máximo de 0,98, enquanto os valores VIF mínimo para as cidades foi de 1,01 e o máximo de 1,34. Portanto, não houve multicolinearidade entre as variáveis independentes. 
Na Análise de Regressão Linear Múltipla foi empregado o método Stepwise pelo fato de ter um número elevado de variáveis independentes (20 ao todo), além de evitar a multicolinearidade entre as variáveis do modelo de pesquisa. No método Stepwise "as variáveis independentes são acrescentadas desde que seus coeficientes de correlação parcial sejam estatisticamente significantes" (Hair Jr. et al., 2009, p. 151). O Stepwise utiliza como parâmetro para adicionar variáveis se os valores de p forem iguais ou menores que 0,05, e para excluir variáveis se os valores forem iguais ou maiores que 0,10 .

Do total de 20 variáveis independentes testadas, verificou-se pelos resultados obtidos dos coeficientes de regressão (Tabela 3) que ao todo cinco dessas variáveis apresentaram relação significativa com a variável dependente DTI. Das cinco variáveis independentes significantes, três variáveis são da dimensão Inovação: Novas tecnologias adotadas por empresas do setor turístico, Projetos de inovação para melhoria de serviços turísticos, e Diferentes serviços turísticos comparados a outros destinos; e duas são da dimensão Sustentabilidade: Planejamento urbanístico e Energia elétrica pela cidade.

Vale destacar que a existência de Novas tecnologias (QRcode, RFID, NFC etc.) adotadas por empresas do setor turístico se apresentou como a maior influenciadora da percepção como DTI tanto em Natal $(\beta=0,439 ; t=5,623$; $p<0,001)$ quanto em São Paulo $(\beta=0,360 ; t=4,110 ; p<0,001)$. Logo a seguir veio o Planejamento urbanístico como o maior influenciador da percepção como DTI tanto em São Paulo ( $\beta=0,348 ; t=3,973 ; p<0,001)$ quanto no Rio de Janeiro $(\beta=0,345 ; t=3,578 ; p<0,001)$. Outras duas variáveis tiveram impacto positivo de influência na percepção como DTI: Projetos de inovação para melhoria de serviços turísticos em Natal $(\beta=0,293$; $t=3,966$; $p<0,001)$ e Rio de Janeiro $(\beta=0,282 ; t=3,141 ; p<0,002)$, e Diferentes serviços turísticos comparados a outros destinos apenas em Natal $(\beta=0,246 ; t=3,323 ; p<0,002)$. Cabe destacar a variável Energia elétrica pela cidade, que obteve um peso relativo mais baixo comparado às outras variáveis influenciadoras da percepção como DTI no Rio de Janeiro, e ainda apresentou uma relação inversa, pois tanto o $\beta=-0,238$ quanto o $t=-2,490$ foram negativos, apesar de significativo em $\mathrm{p}<0,014$.

Fonte: Os autores (2020)

A avaliação do coeficiente de determinação $\left(R^{2}\right)$ indica o poder explicativo da regressão, ou seja, mostra o quanto da variação na variável dependente pode ser explicado pelas variações nas variáveis independentes estudadas no modelo (Corrar et al., 2007). Nas ciências sociais e comportamentais, o $\mathrm{R}^{2}=26 \%$ pode ser classificado como de efeito grande, $\mathrm{R}^{2}=13 \%$ como efeito médio e o $\mathrm{R}^{2}=2 \%$ como de efeito pequeno (Cohen, 1988). Nos resultados alcançados pela Análise de Regressão (Tabela 3), os R² de Natal (56,5\%) e São Paulo (32,7\%) do modelo proposto apresentaram uma relação forte, enquanto no Rio de Janeiro (21,3\%) o relacionamento foi considerado moderado.

Avaliando o $\mathrm{R}^{2}$ por cidade, em Natal observa-se que a variância do conjunto das três variáveis independentes da dimensão Inovação (Novas tecnologias, Projetos de inovação, e Diferentes serviços turísticos) alcançaram um poder explicativo forte sobre a variável dependente DTI. Já no Rio de Janeiro, uma variável independente da dimensão Inovação (Projetos de inovação, a mesma variável em Natal) e duas variáveis independentes da dimensão Sustentabilidade (Planejamento urbanístico e Energia elétrica) alcançaram um poder explicativo moderado sobre a variável dependente DTI. Enquanto em São Paulo verifica-se que uma variável independente da dimensão Inovação (Novas tecnologias, a mesma variável em Natal) e uma variável independente da dimensão Sustentabilidade (Planejamento urbanístico, a mesma variável no Rio de Janeiro) alcançaram um poder explicativo forte sobre a variável dependente DTI. Ao se analisar as três cidades de forma conjunta, percebe-se que indicadores 
das dimensões de Inovação e Sustentabilidade tiveram poder de influência sobre DTI, principalmente as variáveis Novas tecnologias, Projetos de inovação e Planejamento urbanístico, presentes em duas das cidades avaliadas (Figura 2).

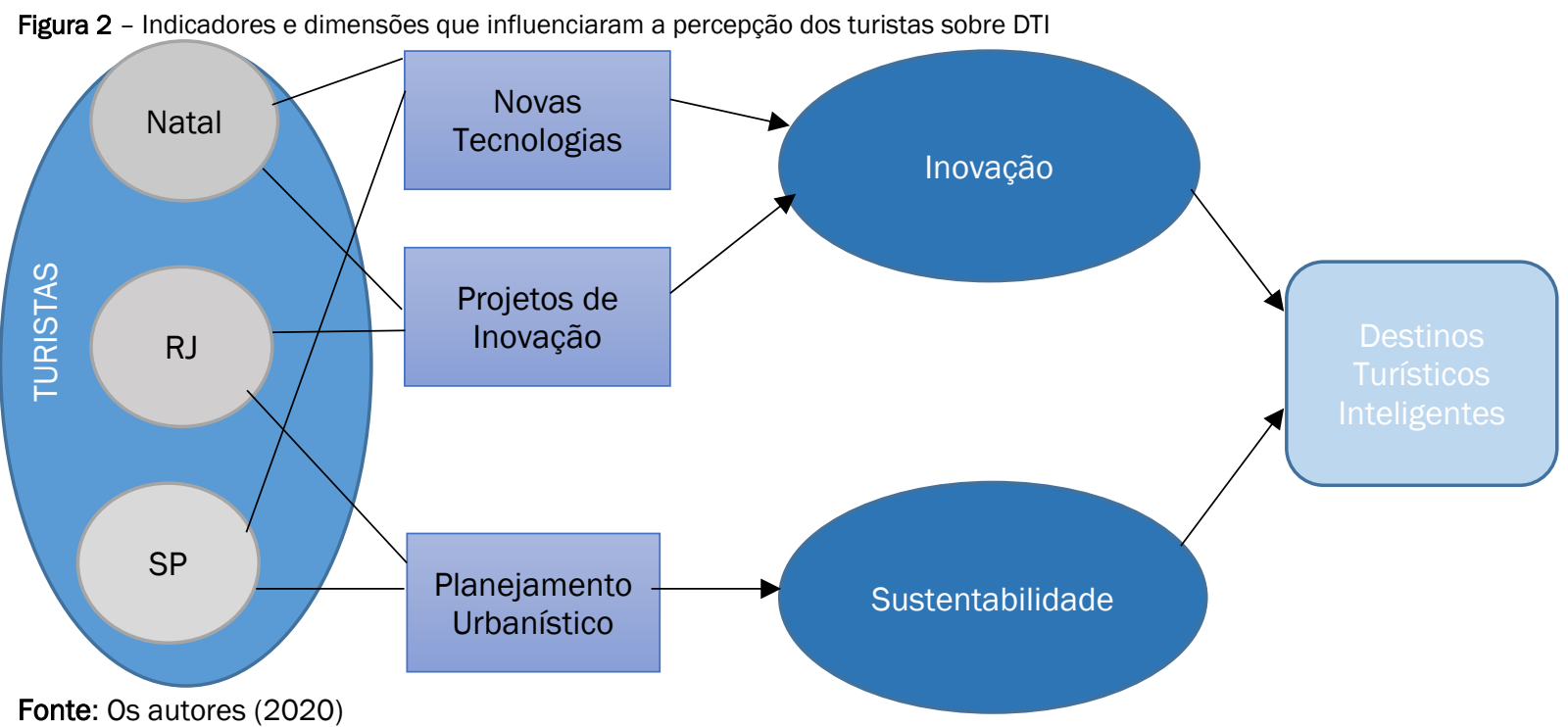

Portanto, para sintetizar os principais resultados dessa pesquisa, a Figura 2 apresenta um modelo com os indicadores Novas tecnologias, Projetos de inovação e Planejamento urbanístico, e suas dimensões respectivas Inovação e Sustentabilidade, que mais influenciaram a percepção dos turistas sobre DTI em pelo menos duas cidades avaliadas.

\subsection{Discussão dos resultados}

Pelos resultados da Análise de Regressão Linear Múltipla, verificou-se que indicadores das dimensões Inovação e Sustentabilidade influenciaram a variável dependente DTI. Dessas duas dimensões, as variáveis Novas tecnologias (Inovação), Projetos de inovação (Inovação) e Planejamento urbanístico (Sustentabilidade) representaram as maiores influenciadoras da percepção de DTI em pelo menos duas das três cidades. Por outro lado, variáveis específicas das dimensões Acessibilidade e Tecnologia não apresentaram relações significativas com DTI, embora a variável Novas tecnologias da dimensão Inovação tenha se mostrado significativa. Portanto, uma discussão sobre as dimensões Inovação e Sustentabilidade (e seus indicadores) - as que mais afetaram a percepção de DTI - faz-se necessária.

Os resultados dessa pesquisa podem ser relacionados a estudos sobre Inovação e DTI, como o de Boes et al. (2016), ao indicarem que para o destino se tornar um DTI precisa ter objetivos voltados para a inovação, pois facilita o desenvolvimento de um ecossistema no destino turístico. Assim, a implantação de uma estratégia de DTI vai favorecer a inovação para consolidar o destino, sobretudo aquele que está se capacitando para atuar na gestão e tomada de decisões (Femenia-Serra \& Ivars-Baidal, 2018; Femenia-Serra, Perles-Ribes et al., 2019), como também na cooperação entre os stakeholders (Ivars-Baidal et al., 2019). A inovação acrescenta uma perspectiva abrangente que permite entender o desenvolvimento e gerenciamento contínuo de um DTI, logo, o foco deveria ser em destinos inteligentes como destinos inovadores (Williams et al., 2020). Para facilitar a inovação, é necessário que os destinos tenham acesso a novas tecnologias e conhecimento de ponta (Pierre, 2019). As inovações tecnológicas reúnem os stakeholders interessados nos ecossistemas das atividades turísticas nos destinos (Buhalis, 2019).

Neste estudo, a existência de Novas tecnologias (QRcode, RFID, NFC etc.) adotadas por empresas do setor turístico (hotéis, restaurantes, bares etc.) se mostrou essencial para avaliação das cidades como um DTI, na percepção dos turistas que visitaram Natal e São Paulo. Para Femenia-Serra, Neuhofer et al. (2019), o uso de novas tecnologias é capital para um DTI. O turismo está empregando cada vez mais novas tecnologias, por exemplo: QRcode, Radio Frequency Identification (RFID), Near Field Communication (NFC), Internet das Coisas, Internet 5G, tecnologias vestíveis (wearables), impressão 3D, Blockchain e Criptomoedas, redes de sensores sem fio e beacons inteligentes, 
gamificação, computação em nuvem, computação ubíqua, inteligência artificial, machine learning (Boes et al., 2015; Paska, 2018; Buhalis, 2020). 0 turismo inteligente foca em tirar vantagem dessas tecnologias, porque juntas elas formam o ecossistema de DTI com o objetivo de fortalecer a inovação e criar modelos de negócio no turismo (Gretzel, 2018).

As empresas de tecnologia podem dar apoio a integração e uso de novas ferramentas, além de facilitar a colaboração para promover a inovação e a disseminação de TIC nos destinos (Öberg, Ribe, Glaumann, Gjelstrup, \& Berntsson, 2017). Afinal, as tecnologias são fundamentais no contexto dos DTI, ao estimular que turistas se comuniquem diretamente e interajam com os stakeholders do turismo de maneira mais eficiente (Jeong \& Shin, 2019). Portanto, os DTI são um campo em rápido desenvolvimento que só crescerá em importância associado aos avanços das novas tecnologias (Gretzel et al., 2018).

A variável Projetos de inovação para melhoria de produtos e serviços turísticos teve influência significativa na percepção como DTI para os turistas que visitaram Rio de Janeiro e Natal. Estudo de Strömdahl et al. (2014) na Suécia constatou a existência de relação entre Projetos de inovação e DTI, como comprova os projetos a seguir: a) Viajante perfeito: visa preencher a lacuna entre o transporte público e privado por meio de um serviço de corretagem focado em soluções para viagens diárias; b) Viajante virtual: como a visualização e a simulação podem apoiar o envolvimento do viajante no processo de design de novas soluções de transporte; c) Living Lab: desenvolveu um serviço de viagem que foi implementado em um ambiente de teste em laboratório. De acordo com as Nações Unidas (United Nations, 2016), governos estão alocando recursos para pesquisas em projetos de inovação em DTI, e incentivando a utilização de infraestruturas inovadoras como parques científicos, incubadoras, hubs de inovação e Living Labs para ajudar no desenvolvimento de ideias para cidades inteligentes. Esses Living Labs exemplificam a cultura de inovação que permeia os DTI (Gretzel \& Scarpino Johns, 2018).

Os resultados desse estudo podem dialogar com pesquisas sobre Sustentabilidade e DTI. Gomis-López e GonzálezReverté (2020) falam da importância da conexão entre Sustentabilidade e DTI por meio da implementação de tecnologias como estratégia do destino para realizar uma gestão ambiental mais eficiente. Os DTI estão se equipando com infraestruturas tecnológicas para lidar melhor com o meio ambiente - superlotação, clima, tráfego, consumo de energia elétrica (Gretzel \& Scarpino Johns, 2018). Com a aplicação eficiente de tecnologias inteligentes, os DTI podem se concentrar na gestão sustentável dos destinos (Mehraliyev et al., 2019). Em nível sistêmico, a sustentabilidade ambiental é uma prioridade para viabilizar o ecossistema de um DTI (Gretzel, Sigala et al., 2015; Gretzel, Werthner et al., 2015).

Em São Paulo e Rio de Janeiro, o Planejamento urbanístico influenciou a percepção dos turistas sobre a noção de DTI, corroborando as ideias de Gretzel (2018), ao afirmar que o foco nos destinos onde foram implementados os conceitos de turismo inteligente tem sido o planejamento urbano. Os DTI estão empregando tecnologias nos planejamentos urbanos, facilitando principalmente o uso de espaços públicos, estacionamentos e questões de segurança (SmartCitiesWorld, 2018). Internet das coisas, 5G e inteligência artificial irão possibilitar o acesso a dados em tempo real nas cidades, sendo ferramentas eficientes para o planejamento e gestão urbana em destinos sustentáveis no futuro (Paska, 2018).

O turismo inteligente é um componente chave para o planejamento urbano do destino, fornecendo estratégias de renovação para o local e soluções tecnológicas que possam enfrentar as demandas urbanas, como mobilidade turística e overtourism (Gomis-López \& González-Reverté, 2020). Incorporar tecnologias em infraestruturas urbanas de tráfego, por exemplo, câmeras, gera mais opções de mobilidade para o turista em grandes cidades onde há engarrafamentos (Gretzel, 2018). Como ressaltado por Santos e Gândara (2019), a sustentabilidade é fundamental para o desenvolvimento turístico sustentável e para a competitividade de um DTI.

Embora várias pesquisas comprovem que a presença de Tecnologia tem impacto direto na percepção de um DTI (Sigala et al., 2015; Buhalis \& Amaranggana, 2015; Boes et al., 2016; Gretzel \& Scarpino Johns, 2018; Gretzel; Ivars-Baidal et al., 2019), os resultados da Análise de Regressão não apresentaram variáveis dessa dimensão influenciando os turistas investigados. Por outro lado, ressalta-se que a variável Novas tecnologias (QRcode, RFID, NFC etc.) da dimensão de Inovação teve impacto significativo na percepção de Natal e São Paulo como DTI. Além disso, obteve-se coeficientes de Pearson com correlação baixa significativa entre as variáveis Wi-fi e Aplicativos turísticos com informações da cidade comparando com DTI em Natal e Rio de Janeiro. Assim como houve correlações baixas significativas com DTI considerando as variáveis tecnológicas Sites e Perfis de redes sociais com informações turísticas da cidade apenas em Natal. 0 que, portanto, comprova a importância da Tecnologia no 
contexto de DTI no estudo realizado, e reafirmando o uso e utilidade das tecnologias pelos turistas em um DTI com o intuito de satisfazer as necessidades antes e durante a viagem (SEGITTUR, 2016; Buhalis, 2020).

Diferentemente de outras pesquisas sobre Acessibilidade e DTI que discorrem sobre a importância do relacionamento entre essas áreas (Buhalis \& Amaranggana, 2014; Boes et al., 2016; Santos, Souza Neto, Pereira, Gândara, \& Silva, 2016), nesta pesquisa, Acessibilidade não apresentou relações significativas com DTI. Uma possível explicação para este fenômeno seria de que os respondentes provavelmente não apresentavam nenhum tipo de deficiência física, auditiva ou visual. Porém, verificou-se correlação significativa moderada ou baixa entre Acessibilidade e DTI nas três cidades examinadas, considerando as variáveis de Acessibilidade nas ruas para turistas, Transporte público adaptado e Atrativos turísticos acessíveis. Portanto, Acessibilidade é um fator essencial em um DTI, ofertando uma experiência positiva ao turista ao garantir direito de igualdade de oportunidade para todos, mediante à inclusão dos portadores de necessidades especiais, além de promover competitividade ao destino e qualidade de vida ao residente (Santos et al., 2016; SEGITTUR, 2016).

\section{CONCLUSÕES}

No contexto de implantação de estratégias voltadas ao desenvolvimento do turismo e à adoção de tecnologias com o objetivo de transformar destinos em DTI, estão envolvidas decisões complexas e um conjunto de altos investimentos públicos e privados que não devem ser desprezados pelos gestores turísticos, uma vez que a proposta é atrair mais turistas e aumentar a competitividade frente a outros destinos.

Com as dificuldades inerentes à decisão sobre quais dimensões priorizar no processo de gestão de um DTI, sendo a literatura escassa neste sentido (Gajdosík, 2019), propõe-se que a ordenação das ações leve em consideração a percepção do turista e seu processo de tomada decisão em relação à escolha de visitar um destino inteligente. Os turistas são cada vez mais adeptos de tecnologias, não somente para aperfeiçoar a própria experiência turística, como também para realizar uma interação em tempo real e participar de processos de cocriação com outros stakeholders em um DTI (Femenia-Serra, Neuhofer et al., 2019).

Desta forma, recomenda-se um conjunto de dimensões prioritárias para a implantação do DTI, as quais podem ser efetivamente percebidas pelos turistas como valor agregado, o que permitiria um retorno mais rápido e menos arriscado dos investimentos efetuados por gestores públicos e privados. Ademais, um redirecionamento rumo ao nível de um DTI pode contribuir para a captação de novos recursos que possam dar suporte a ações complementares e basilares para a consolidação do DTI.

Esse estudo teve como objetivo investigar as dimensões que influenciam a percepção dos turistas sobre DTI em três destinos de perfis diferentes (Natal, Rio de Janeiro e São Paulo), tendo como base as dimensões dos modelos teóricos espanhóis de DTI (INVAT.TUR, 2015; SEGITTUR, 2016), e um estudo qualitativo inicial para a definição dos itens das dimensões utilizados na survey da pesquisa. $\mathrm{Na}$ análise de resultados, verificou-se que houve um destaque maior na percepção das dimensões de Inovação e Sustentabilidade influenciando a percepção de DTI para os turistas dos três destinos. Em menos intensidade, foram localizadas correlações significativas, porém baixas, entre as dimensões de Tecnologia e Acessibilidade com DTI.

Vale realçar que a compreensão de DTI não deve se limitar à adoção e implantação de tecnologias avançadas para uso dos stakeholders (Gretzel \& Scarpino Johns, 2018; Johnson \& Samakovlis, 2019; Jovicic, 2019), mas vista como uma interdependência de outros aspectos como a Sustentabilidade, Inovação e Acessibilidade, como notado nos resultados desta pesquisa. Além das tecnologias, o destino precisa se guiar por uma estratégia de desenvolvimento e gestão do turismo, com implicações para a governança e estratégia do destino (Gretzel, 2018). Portanto, a "inteligência" dos destinos não será condicionada à utilização de tecnologias, mas englobará uma estratégia compartilhada pelos stakeholders do turismo, com soluções adaptadas para cada destino (Ivars-Baidal et al., 2019).

\subsection{Contribuições teóricas e práticas}

Estudos realizados com ênfase em DTI foram realizados em vários contextos (Femenia-Serra \& Neuhofer, 2018; Johnson \& Samakovlis, 2019; Mehraliyev et al., 2019, 2020). Entretanto, existem poucas pesquisas de DTI com enfoque no turista (Femenia-Serra, Neuhofer et al., 2019; Femenia-Serra, Perles-Ribes et al., 2019; Gajdosík, 2019), e com a maioria desses estudos utilizando dados secundários, casos de melhores práticas ou estudos 
empíricos descritivos. Esta pesquisa é uma das primeiras a conceitualizar e testar estatisticamente um modelo de DTI apoiado na percepção de turistas em três destinos com perfis diferenciados.

Como principal contribuição teórica, um modelo de DTI foi desenvolvido a partir das dimensões de Inovação e Sustentabilidade, sendo que os seguintes indicadores se apresentaram como maiores influenciadoras da percepção de DTI pelos turistas: Novas tecnologias (QRcode, RFID, NFC etc.) adotadas por empresas do setor turístico (hotéis, restaurantes, bares etc.); Projetos de inovação para melhoria de produtos e serviços turísticos; e Planejamento urbanístico da cidade.

Em termos de contribuições gerenciais, pretende-se que esse modelo ajude os destinos a priorizarem determinadas dimensões no processo de implantação de novas ações de DTI. Desta forma, a atividade turística se beneficiará ao ter disponível um modelo sobre as dimensões de DTI arquitetado a partir das preferências dos principais interessados, os turistas (Mehraliyev et al., 2020), servindo para fomentar a inovação e a competitividade nos destinos. As informações proporcionadas pelo modelo teórico podem ser um norteador de políticas e práticas que estimulem o crescimento inteligente, sustentável e integrador, liderado pelas secretarias municipais e estaduais de turismo para engendrar inovação ao setor.

É importante destacar que as dimensões e indicadores de DTI podem variar conforme o destino (Freitas \& Mendes Filho, 2020). Portanto, as dimensões e indicadores a serem adotados por um destino devem se adaptar às necessidades e recursos disponíveis na cidade e região, favorecendo aquelas com estruturas organizacionais mais ágeis e propensas à colaboração público-privada, e bem equipadas em termos de recursos econômicos e humanos (Ivars-Baidal et al., 2019).

\subsection{Limitações e pesquisas futuras}

Este estudo tem limitações que precisam ser apresentadas. A coleta de dados foi realizada em três cidades brasileiras com um total de 303 respondentes. Sugere-se que as próximas pesquisas sobre DTI sejam realizadas em destinos de outras regiões brasileiras ou outros países, de modo a verificar se as dimensões e indicadores trabalhados nesta pesquisa serão percebidos pelos turistas nesses lugares. Outra sugestão é de se promover uma pesquisa de abordagem qualitativa para efeitos de comparação com os resultados quantitativos deste estudo.

\section{AGRADECIMENTOS}

O presente trabalho foi realizado com apoio do CNPq - Conselho Nacional de Desenvolvimento Científico e Tecnológico. Os autores informam que o artigo faz parte da pesquisa "Destinos turísticos inteligentes: desenvolvimento de um modelo sobre as dimensões que afetam o processo de decisão do turista", aprovada no Edital Universal CNPq 01/2016. Nosso agradecimento ao CNPq pelo apoio financeiro para realização da pesquisa.

\section{REFERÊNCIAS}

Boes, K., Buhalis, D., \& Inversini, A. (2015). Conceptualising smart tourism destination dimensions. In I. Tussyadiah \& A. Inversini (Eds.), Information and Communication Technologies in Tourism 2015 (pp. 391-404). https://doi.org/10.1007/978-3-319-14343-9 29

Boes, K., Buhalis, D., \& Inversini, A. (2016). Smart tourism destinations: ecosystems for tourism destination competitiveness. International Journal of Tourism Cities, 2(2), 108-124. https://doi.org/10.1108/IJTC-12-2015$\underline{0032}$

Buhalis, D. (2019). Technology in tourism-from information communication technologies to eTourism and smart tourism towards ambient intelligence tourism: a perspective article. Tourism Review, 75(1), $267-272$. https://doi.org/10.1108/TR-06-2019-0258

Buhalis, D., \& Amaranggana, A. (2014). Smart Tourism Destinations. In Z. Xiang \& I. Tussyadiah (Eds.), Information and Communication Technologies in Tourism 2014 (pp. 553-564). https://doi.org/10.1007/978-3-319-03973$\underline{240}$

Buhalis, D., \& Amaranggana, A. (2015). Smart tourism destinations enhancing tourism experience through personalisation of services. In I. Tussyadiah \& A. Inversini (Eds.), Information and Communication Technologies in Tourism 2015 (pp. 377-389). https://doi.org/10.1007/978-3-319-14343-9 28 
Buonincontri, P., \& Micera, R. (2016). The experience co-creation in smart tourism destinations: a multiple case analysis of European destinations. Information Technology \& Tourism, 16(3), 285-315. https://doi.org/10.1007/s40558-016-0060-5

Cacho, A., Mendes-Filho, L., Estaregue, D., Moura, B., Cacho, N., Lopes, F., \& Alves, C. (2016). Mobile tourist guide supporting a smart city initiative: a Brazilian case study. International Journal of Tourism Cities, 2(2), 164-183. https://doi.org/10.1108/IJTC-12-2015-0030

Cimbaljević, M., Stankov, U., \& Pavluković, V. (2019). Going beyond the traditional destination competitiveness reflections on a smart destination in the current research. Current Issues in Tourism, 22(20), 2472-2477. https://doi.org/10.1080/13683500.2018.1529149

Cohen, J. (1988). Statistical Power Analysis for the Behavioral Sciences (2nd ed.). New York: Psychology Press.

Corrar, L. J., Paulo, E., \& Dias Filho, J. M. (2007). Análise multivariada para os cursos de administração, ciências contábeis e economia. São Paulo: Atlas.

Femenia-Serra, F., \& Ivars-Baidal, J. A. (2021). Do smart tourism destinations really work? The case of Benidorm. Asia Pacific Journal of Tourism Research, 26(4), 365-384. https://doi.org/10.1080/10941665.2018.1561478

Femenia-Serra, F., \& Neuhofer, B. (2018). Smart tourism experiences: conceptualisation, key dimensions and research agenda. Investigaciones Regionales - Journal of Regional Research, 42, 129-150.

Femenia-Serra, F., Neuhofer, B., \& Ivars-Baidal, J. A. (2019). Towards a conceptualisation of smart tourists and their role within the smart destination scenario. The Service Industries Journal, 39(2), 109-133. https://doi.org/10.1080/02642069.2018.150845

Femenia-Serra, F., Perles-Ribes, J. F., \& Ivars-Baidal, J. (2019). Smart destinations and tech-savvy millennial tourists: hype versus reality. Tourism Review, 74(1), 63-81. Retrieved from https://doi.org/10.1108/TR-02-2018-0018

Freitas, H. B. B. de, \& Mendes Filho, L. (2020). Iniciativas de destinos turísticos inteligentes na cidade de Natal-RN: Uma abordagem qualitativa. Rosa Dos Ventos - Turismo e Hospitalidade, 12(4), 997-1016. https://doi.org/10.18226/21789061.v12i4p997

Gajdosík, T. (2019). Smart tourists as a profiling market segment: Implications for DMOs. Tourism Economics, 26(6), 1-21. https://doi.org/10.1177/1354816619844368

Gomes, E. L., Gândara, J. M., \& Ivars-Baidal, J. A. (2017). É importante ser um destino turístico inteligente? A compreensão dos gestores públicos dos destinos do Estado do Paraná. Revista Brasileira de Pesquisa Em Turismo, 11(3), 503-536. https://doi.org/10.7784/rbtur.v11i3.1318

Gomis-López, J. M., \& González-Reverté, F. (2020). Smart Tourism Sustainability Narratives in Mature Beach Destinations. Contrasting the Collective Imaginary with Reality. Sustainability, 12(12), 1-17. https://doi.org/10.3390/su12125083

Gretzel, U. (2018). From smart destinations to smart tourism regions. Investigaciones Regionales - Journal of Regional Research, 42, 171-184.

Gretzel, U., Ham, J., \& Koo, C. (2018). Creating the City Destination of the Future - The Case of Smart Seoul. In Y. Wang, A. Shakeela, A. Kwek, \& C. Khoo-Lattimore (Eds.), Managing Asian Destinations. Springer. https://doi.org/10.1007/978-981-10-8426-3_12

Gretzel, U., \& Scarpino Johns, M. (2018). Destination Resilience and Smart Tourism Destinations. Tourism Review International, 22(3), 263-276. https://doi.org/10.3727/154427218X15369305779065

Gretzel, U., Sigala, M., Xiang, Z., \& Koo, C. (2015). Smart tourism: foundations and developments. Electronic Markets, 25(3), 179-188. https://doi.org/10.1007/s12525-015-0196-8

Gretzel, U., Werthner, H., Koo, C., \& Lamsfus, C. (2015). Conceptual foundations for understanding smart tourism ecosystems. Computers in Human Behavior, 50, 558-563. https://doi.org/10.1016/j.chb.2015.03.043

Hair Jr., J. F., Black, W. C., Babin, B. J., Anderson, R. E., \& Tatham, R. L. (2009). Análise multivariada de dados (6a ed.). Porto Alegre: Bookman.

INVAT.TUR. (2015). Manual Operativo para la configuración de destinos turísticos inteligentes. Recuperado July 28 , 2020, de: www.slideshare.net/invattur/manual-operativo-para-la-configuracin-dedestinos-\%0Ainteligentes

Ivars-Baidal, J., Celdrán-Bernabeu, M. A., Mazón, J.-N., \& Perles-Ivars, Á. F. (2019). Smart destinations and the evolution of ICTs: a new scenario for destination management? Current Issues in Tourism, 22(13), 1581-1600. https://doi.org/10.1080/13683500.2017.1388771 
Jeong, M., \& Shin, H. H. (2019). Tourists' Experiences with Smart Tourism Technology at Smart Destinations and Their Behavior Intentions. Journal of Travel Research, p. 1-14. https://doi.org/10.1177/0047287519883034

Johnson, A.-G., \& Samakovlis, I. (2019). A bibliometric analysis of knowledge development in smart tourism research. Journal of Hospitality and Tourism Technology, 10(4), 600-623. https://doi.org/10.1108/JHTT-07-2018$\underline{0065}$

Jovicic, D. Z. (2019). From the traditional understanding of tourism destination to the smart tourism destination. Current Issues in Tourism, 22(3), 276-282. https://doi.org/10.1080/13683500.2017.1313203

Koo, C., Mendes-Filho, L., \& Buhalis, D. (2019). Guest editorial - Smart tourism and competitive advantage for stakeholders. Tourism Review, 74(1), 1-4. https://doi.org/10.1108/TR-02-2019-208

Lamsfus, C., Martín, D., Alzua-Sorzabal, A., \& Torres-Manzanera, E. (2015). Smart Tourism Destinations: An Extended Conception of Smart Cities Focusing on Human Mobility. In I. Tussyadiah \& A. Inversini (Eds.), Information and Communication Technologies in Tourism 2015 (pp. 363-375). https://doi.org/10.1007/978-3-319-14343$\underline{927}$

Lamsfus, C., Wang, D., Alzua-Sorzabal, A., \& Xiang, Z. (2015). Going Mobile: Defining Context for On-the-Go Travelers. Journal of Travel Research, 54(6), 691-701. https://doi.org/10.1177/0047287514538839

Li, Y., Hu, C., Huang, C., \& Duan, L. (2017). The concept of smart tourism in the context of tourism information services. Tourism Management, 58, 293-300. https://doi.org/10.1016/i.tourman.2016.03.014

Lima, D. S. M., Mendes Filho, L., Correa, C. H. W., \& Mayer, V. F. (2021). Análise da cidade de Natal/RN como Destino Turístico Inteligente a partir do modelo INVAT.TUR. Marketing \& Tourism Review, 6(1), 1-39. https://doi.org/10.29149/mtr.v6i1.6413

Mehraliyev, F., Chan, I. C. C., Choi, Y., Koseoglu, M. A., \& Law, R. (2020). A state-of-the-art review of smart tourism research. Journal of Travel \& Tourism Marketing, 37(1), 78-91. https://doi.org/10.1080/10548408.2020.1712309

Mehraliyev, F., Choi, Y., \& Köseoglu, M. A. (2019). Progress on smart tourism research. Journal of Hospitality and Tourism Technology, 10(4), 522-538. https://doi.org/10.1108/JHTT-08-2018-0076

Mendes Filho, L., Silva, J. C., \& da Silva, D. S. (2019). Percepções e perspectivas de destino turístico inteligente: um estudo de caso com a secretaria municipal de turismo em Natal/RN. Revista Turismo Estudos e Práticas (RTEP), 8(1), 98-124.

Neuhofer, B., Buhalis, D., \& Ladkin, A. (2012). Conceptualising technology enhanced destination experiences. Journal of Destination Marketing \& Management, 1(1-2), 36-46. https://doi.org/10.1016/i.jdmm.2012.08.001

Öberg, J., Ribe, J., Glaumann, M., Gjelstrup, A., \& Berntsson, G. L. (2017). Connected things 2017: Smart public transport. Recuperado de: https://www.teliacompany.com/globalassets/teliacompany/documents/news/connected things-publictransport.pdf

Paska, D. (2018). Digitalized water and smart cities - how can telecommunication networks be used for environmental resilience? ITU Journal: ICT Discoveries, 2, 1-8.

Pierre, J. (2019). Multilevel governance as a strategy to build capacity in cities: Evidence from Sweden. Journal of Urban Affairs, 41(1), 103-116. https://doi.org/10.1080/07352166.2017.1310532

Santos-Júnior, A., Almeida-García, F., Morgado, P., \& Mendes-Filho, L. (2020). Residents' quality of life in smart tourism destinations: A theoretical approach. Sustainability, 12(20), 1-24. https://doi.org/10.3390/su12208445

Santos-Júnior, Adalberto, Biz, A. A., Almeida-García, F., \& Mendes-Filho, L. (2019). Entendiendo la gobernanza de los destinos turísticos inteligentes: el caso de florianópolis - Brasil. International Journal of Information Systems and Tourism, 4(4), 29-39.

Santos Júnior, A., Mendes Filho, L., García, F. A., \& Simões, J. M. (2017). Smart Tourism Destinations: un estudio basado en la visión de los stakeholders. Revista Turismo Em Análise, 28(3), 358-379. https://doi.org/10.11606/issn.1984-4867.v28i3p358-379

Santos, S. R., \& Gândara, J. M. G. (2019). Experiência Turística em Destino Histórico no Nordeste Brasileiro sob o Viés de Destino Turístico Inteligente. Rosa Dos Ventos - Turismo e Hospitalidade, 11(2), 435-453. https://doi.org/10.18226/21789061.v11i2p435\%0D

Santos, S. R., Souza Neto, V. R., Pereira, L. R. S., Gândara, J. M. G., \& Silva, S. R. X. (2016). Destino Turístico Inteligente: Acessibilidade no centro histórico de São Luís - Maranhão, um estudo sobre a reputação Online no TripAdvisor. Marketing \& Tourism Review, 1(2), 1-27. https://doi.org/10.29149/mtr.v1i2.3843 
SEGITTUR. (2016). Normalización Destinos Turísticos Inteligentes. Recuperado em July 27, 2020, de https://www.segittur.es/destinos-turisticos-inteligentes/proyectos-destinos/normalizacion/

SmartCitiesWorld. (2018). Are Europe's cities ready for autonomous mobility? Recuperado em June 19, 2019, de https://www.smartcitiesworld.net/opinions/opinions/are-europes-cities-ready-for-autonomous-mobility

Strömdahl, A., Arby, H., Kuschel, M., Karlsson, M., Billger, M., \& Holmberg, P.-E. (2014). GO:SMART - Mistra Urban Futures. Gothenburg.

United Nations. (2016). Smart cities and infrastructure. Recuperado de: https://unctad.org/meetings/en/SessionalDocuments/ecn162016d2_en.pdf

URBAN SYSTEM. (2020). Ranking Connected Smart Cities 2020. Recuperado em 20, 2020, de https://ranking.connectedsmartcities.com.br/resultados.php

Vecchio, P. Del, Mele, G., Ndou, V., \& Secundo, G. (2018). Creating value from Social Big Data: Implications for Smart Tourism Destinations. Information Processing and Management, 54, 847-860. https://doi.org/10.1016/j.ipm.2017.10.006

Wang, D., Li, X., \& Li, Y. (2013). China's smart destination initiative: a taste of the service-dominant logic. Journal of Destination Marketing \& Management, 2(2), 59-61. https://doi.org/10.1016/j.jdmm.2013.05.004

Williams, A. M., Rodriguez, I., \& Makkonen, T. (2020). Innovation and smart destinations: Critical insights. Annals of Tourism Research, 83. https://doi.org/10.1016/j.annals.2020.102930.

\section{Informações dos Autores}

\section{Luiz Mendes Filho}

Professor Associado do Departamento de Turismo e docente permanente do Programa de Pós-Graduação em Turismo (PPGTUR) da Universidade Federal do Rio Grande do Norte (UFRN). PhD em Administração (Auckland University of Technology, Nova Zelândia) com pós-doutorado em Turismo (Bournemouth University, Inglaterra). Possui mestrado em Engenharia de Produção (UFRN) e bacharelado em Ciências da Computação (UFRN). Líder do Grupo de Estudos em Gestão do Turismo (GESTUR) UFRN/CNPq.

Contribuição no artigo: Concepção da pesquisa, revisão da literatura, coleta de dados, análise de dados e discussão.

Email: luiz.mendes@ufrn.br

ORCID: https://orcid.org/0000-0002-9175-8903

\section{Verônica Feder Mayer}

Doutora em Administração pelo Instituto COPPEAD de Administração da Universidade Federal do Rio de Janeiro, com extensão nos EUA, e pós-doutorado em turismo na Escola de Artes, Ciências e Humanidades da Universidade de São Paulo. É professora associada da Faculdade de Turismo e Hotelaria da Universidade Federal Fluminense, vice coordenadora do PPGTUR/UFF, e pesquisadora líder do LABCONS - Laboratório de Estudos Comportamentais em Turismo. Linhas de pesquisa: marketing, consumo e novas tecnologias no turismo; economia comportamental aplicada ao turismo; bem-estar subjetivo em turismo e hotelaria.

Contribuição no artigo: Metodologia, coleta de dados, análise de dados e discussão.

Email: veronicamayer@id.uff.br

ORCID: https://orcid.org/0000-0002-7543-5215

\section{Cynthia Harumy Watanabe Correa}

Professora Associada da Escola de Artes, Ciências e Humanidades (EACH), da Universidade de São Paulo (USP), vinculada ao Programa de Pós-Graduação em Estudos Culturais. Livre-Docente na área das Ciências Sociais Aplicadas com especialidade em Marketing Turístico Digital pela USP, Doutora em Comunicação Social pela Pontifícia Universidade Católica do Rio Grande do Sul (PUC-RS), com doutorado sanduíche na Université René Descartes - Paris V, Sorbonne. Líder do Grupo de Pesquisa Humanitas Digitalis da USP/CNPq e integrante da Association of Internet Researchers (AoIR).

Contribuição no artigo: Desenvolvimento da pesquisa, coleta de dados, análise de dados e discussão.

Email: cynthiacorrea@usp.br

ORCID: https://orcid.org/0000-0002-9552-9235 